\title{
Health outcomes in Aboriginal populations
}

\author{
Alan Cass \\ ß See related articles pages 577 and 585
}

W hy do Aboriginal Canadian, Maori New Zealander, Aboriginal Australian and Native American babies born today share a pattern of premature morbidity and mortality rather than the expected healthy life-course of the nonindigenous baby in the next crib? Despite marked improvements in the average indicators of health in Western nations, good health is not enjoyed by all. Our indigenous citizens suffer substantial and systematic inequalities that cannot be accounted for by individual make-up or behaviour.

In two articles in this issue, Wenman and colleagues and Tonelli and colleagues explore the factors influencing adverse outcomes in birth and renal replacement respectively for Aboriginal Canadians. ${ }^{1,2}$ In both articles, "Aboriginality" is conceptualized as a risk factor. However, after multivariate analysis in which potential confounders, including socioeconomic status, health-damaging behaviours such as smoking and the presence of comorbidities, were controlled for, "Aboriginality" loses its association with adverse outcomes.

In Australia, despite principles of universal access to health care similar to those of Canada, Aboriginal women are less likely to attend early prenatal care. ${ }^{3}$ Late presentation is associated with an increased risk of low birth weight. ${ }^{4}$ Because of reduced access to prenatal care, Aboriginal women are unlikely to be included in prospective cohort studies, yet they are the most likely to experience adverse birth outcomes. The prospective study by Wenman and colleagues in Edmonton (see page 585) was restricted to women who attended prenatal care before 20 weeks' gestation and thus might understate the risk of adverse birth outcomes for Aboriginal Canadians. The authors also acknowledge that the small number of Aboriginal participants reduced the power of their study to detect a significant association between ethnic origin and adverse outcomes.

Tonelli and colleagues undertook a retrospective cohort study (see page 577) of all patients commencing dialysis in Alberta, Saskatchewan and Manitoba between Jan. 1, 1990, and Dec. 31, 2000. After adjustment for the presence of diabetes and other comorbidities, Aboriginal patients and white patients experienced similar survival rates on dialysis. However, Aboriginal patients received transplants at less than half the rate that white patients did. This is consistent with the reduced access to kidney transplantation experienced by Native Americans ${ }^{5}$ and Australian Aborigines. ${ }^{6}$

Is "Aboriginal race" a risk factor for adverse health out- comes? Undoubtedly. However, we need to unpack the concept of "race" to both explore the interplay of factors that lead to a greater burden of disease and explain poorer treatment outcomes. A range of explanations, including genetic difference, has been proposed. However, in chronic diseases of multifaceted origin, where environmental and socioeconomic factors influence health status, interactions between genetic and environmental factors are complex, and differences in patterns of illness will be attributable to their interaction. ${ }^{7}$ For the foreseeable future, environmental factors will be more readily explicable and should prove more amenable to intervention.

Indigenous women are at a disadvantage. They suffer poorer birth outcomes, including higher rates of low-birthweight infants. As well, as Barker and others have suggested, there is a link between fetal malnutrition, marked by low birth weight or intrauterine growth retardation, and a predisposition to adult chronic diseases. ${ }^{8-10}$ Surveys of Aboriginal Australian health have revealed a high prevalence of smoking, poor nutrition, lack of exercise, obesity and hazardous alcohol intake. ${ }^{11}$ Aboriginal Australian adults have a striking prevalence of the interrelated risk factors for chronic vascular disease: hypertension, diabetes and proteinuria. ${ }^{12}$ The higher prevalence and greater severity of these risk factors are postulated as the variables that explain the relation between "Aboriginality" and poorer health. However, viewing health disparities through a limited biomedical perspective can foster Aborigines being blamed for their own poor health. It is frequently suggested that, if only they would smoke and drink less, Aborigines would experience better health. This view fails to address the broader social determinants of their ill-health.

Evidence supports a relation between socioeconomic position and overall morbidity and mortality. ${ }^{13}$ In Australian Aboriginal communities, strong associations have been shown between the incidence of chronic kidney disease and markers of socioeconomic disadvantage ${ }^{14}$ Chronic disease epidemiologists conceive of disease risk as residing within the individual and his or her behaviour. Social epidemiologists, on the other hand, believe that features of the social and physical environment at the community level directly affect health outcomes..$^{15}$ Notwithstanding this debate, there is indisputable evidence that health behaviour and access to and use of health services are socially and culturally determined. ${ }^{16}$

Effective primary and secondary prevention to address 
risk factors for chronic disease should be directed at critical stages of life. Primary initiatives should include improved access to culturally appropriate prenatal services and screening for and intensive management of diabetes in pregnancy $;^{17}$ encouragement of breast-feeding and other programs to prevent obesity in early childhood; $;^{18,19}$ and provision of nutrition, physical activity and quit-smoking programs. Effective secondary prevention should be directed at the control of blood pressure, diabetes and hyperlipidemia. This will require innovative approaches to the delivery of services in remote areas and increases to the resources and capacity of the indigenous, communitycontrolled health sector. Macroeconomic interventions will be required at all levels of government to improve education and employment opportunities, to regulate tobacco advertising and to improve access to affordable, healthy food in Aboriginal communities. ${ }^{20}$

Effective interventions are available for people with manifestations of complex chronic disease. As Tonelli and colleagues attest, however, equal access to health care does not, by itself, ensure equitable outcomes for indigenous people. Inadequate patient-physician communication and system-related factors have been shown to determine the poorer treatment outcomes experienced by Aboriginal Australian patients. ${ }^{21,22}$ In addressing these deficiencies, we must be sensitive to the attitudes of our indigenous peoples toward our health care systems. They will not otherwise experience acceptable, timely, responsive and high-quality health care services.

Dr. Cass is director of the Policy and Practice Division at The George Institute for International Health, Sydney, Australia.

Competing interests: None declared.

\section{References}

1. Wenman WM, Joffres MR, Tataryn IV, the Edmonton Perinatal Infections Group. A prospective cohort study of pregnancy risk factors and birth outcomes in Aboriginal women. CMA7 2004;171(6):585-9.

2. Tonelli M, Hemmelgarn B, Manns B, Pylypchuk G, Bohm C, Yeates K, et al. Death and renal transplantation among Aboriginal people undergoing dialysis. CMA7 2004;171(6):577-82.

3. Plunkett A, Lancaster P, Huang J, National Perinatal Statistics Unit (Australia). Indigenous mothers and their babies, Australia 1991-1993. Sydney: Australian Institute of Health and Welfare National Perinatal Statistics Unit; 1996.
4. De Costa C, Child A. Pregnancy outcomes in urban Aboriginal women. Med 7 Aust 1996;164(9):523-6.

5. Sequist TD, Narva AS, Stiles SK, Karp SK, Cass A, Ayanian JZ. Access to renal tranplantation among American Indians and Hispanics. Am 7 Kidney Dis 2004; $44(2): 344-52$.

6. Cass A, Cunningham J, Snelling P, Wang Z, Hoy W. Renal transplantation for indigenous Australians: identifying the barriers to equitable access. Ethn Health 2003;8(2):111-9.

7. Baird PA. The role of genetics in population health. In: Evans RG, Barer ML, Marmor TR, editors. Why are some people healthy and others not? The determinants of health of populations. New York: Aldine de Gruyther; 1994. p. 133-59.

8. Barker DJ, Martyn CN. The maternal and fetal origins of cardiovascular disease. 7 Epidemiol Community Health 1992;46(1):8-11.

9. Barker DJ, Hales CN, Fall CH, Osmond C, Phipps K, Clark PM. Type 2 (non-insulin-dependent) diabetes mellitus, hypertension and hyperlipidaemia (syndrome X): relation to reduced fetal growth. Diabetologia 1993;36(1):62-7.

10. Hoy WE, Rees M, Kile E, Mathews JD, Wang Z. A new dimension to the Barker hypothesis: low birthweight and susceptibility to renal disease. Kidney Int 1999;56(3):1072-7.

11. Australian Bureau of Statistics and Australian Institute of Health and Welfare. The bealth and welfare of Australia's Aboriginal and Torres Strait Islander peoples. Canberra: The Bureau; 1999.

12. Hoy W, Mathews JD, McCredie DA, Pugsley DJ, Hayhurst BG, Rees M, et al. The multidimensional nature of renal disease: rates and associations of albuminuria in an Australian Aboriginal community. Kidney Int 1998;54(4):1296-304.

13. Krieger N, Williams DR, Moss NE. Measuring social class in US public health research: concepts, methodologies, and guidelines. Anпи Rev Public Health 1997; 18:341-78

14. Cass A, Cunningham J, Snelling P, Wang Z, Hoy W. End-stage renal disease in indigenous Australians: a disease of disadvantage. Ethn Dis 2002;12:373-8.

15. Macintyre S, Ellaway A. Ecological approaches: rediscovering the role of the physical and social environment. In: Berkman LF, Kawachi I, editors. Social epidemiology. Oxford: Oxford University Press; 2000. p. 332-48.

16. Turrell G, Oldenburg B, McGuffog I, Dent R. Socioeconomic determinants of health: towards a national research program and a policy and intervention agenda. Canberra: Queensland University of Technology, School of Public Health, Ausinfo; 1999.

17. Dabelea D, Pettitt DJ. Intrauterine diabetic environment confers risks for type 2 diabetes mellitus and obesity in the offspring, in addition to genetic susceptibility. F Pediatr Endocrinol Metab 2001;14(8):1085-91.

18. Pettitt DJ, Forman MR, Hanson RL, Knowler WC, Bennett PH. Breastfeeding and incidence of non-insulin-dependent diabetes mellitus in Pima Indians. Lancet 1997;350(9072):166-8

19. Yajnik CS. The lifecycle effects of nutrition and body size on adult adiposity, diabetes and cardiovascular disease. Obes Res 2002;3(3):217-24.

20. Lee AJ, Bonson AP, Yarmirr D, O'Dea K, Mathews JD. Sustainability of a successful health and nutrition program in a remote aboriginal community. Med 7 Aust 1995;162(12):632-5

21. Cass A, Lowell A, Christie M, Snelling PL, Flack M, Marrnganyin B, et al Sharing the true stories: improving communication between Aboriginal patients and healthcare workers. Med F Aust 2002;176(10):466-70.

22. Cunningham J. Diagnostic and therapeutic procedures among Australian hospital patients identified as indigenous. Med f Aust 2002;176(2):58-62.

Correspondence to: Dr. Alan Cass, Director, Policy and Practice Division, The George Institute for International Health, PO Box M201, Missenden Rd., Sydney NSW 2050, Australia; fax (+61 2) 9993 4502; acass@thegeorgeinstitute.org 